\title{
Factors Influencing the Self-efficacy for Moderate Drinking of Undergraduate Students
}

\author{
대학생의 적절음주자기효능감에 영향을 미치는 요인 \\ Kyungmi Woo ${ }^{1}$, Young-Ju Jee ${ }^{2}$ \\ 우경미 ${ }^{1}$, 지영주 ${ }^{2}$ \\ ${ }^{1}$ Assistant Professor, College of Nursing, Dongwon Institude of Science and Technology, Korea, \\ wgm9637@dist.ac.kr
}

${ }^{2}$ Associate Professor, College of Nursing, Kyungnam University, Korea, jeeyoungju@ kyungnam.ac.kr

Corresponding author: Young-Ju Jee

\begin{abstract}
The purpose of this study is to identify the factors influencing the self-efficacy for moderate drinking of undergraduate students. Data were collected through a survey of the undergraduate students from April 20 to June 4, 2019, self-questionnaires from Undergraduate Students. The research tool consists of employment stress, self-efficacy for moderate drinking, alcohol problem, academic stress, major aptitude, and other general characteristics. The collected data were analyzed using Descriptive statistics, Pearson's correlation coefficient, and multiple regression analysis. Based on the results, it was found that the more Employment stress $(\beta=-.08, p=.001)$, Drinking problem $(\beta=-.47, p<.001)$ and Academic stress $(\beta=.15, \mathrm{p}=.006)$ are the self-efficacy for moderate drinking level. Moreover, it was found that the self-efficacy for moderate drinking of undergraduate students' test is necessary to detect early drinking problems in undergraduate students. In addition, it is necessary to operate an in-university intervention clinic on the drinking problem, which is a factor affecting the self-efficacy for moderate drinking. It was found that it was necessary to find solutions to academic stress and employment stress through student counseling.It was found that it was necessary to find solutions to academic stress and employment stress through student counseling.
\end{abstract}

Keywords: Undergraduate Students, Drinking Problem, Job Stress, Academic Stress, Self-efficacy

요약: 본 연구의 목적은 대학생의 적절음주자기효능감에 영향을 미치는 요인을 규명하는 것이다. 데이터는 2019 년 4 월 20 일부터 6 월 4 일까지 학부생의 자기기입식 조사로 수집되었으며, 본 연구의 설문 조사 내용은 취업 스트레스, 자기효능감, 음주 문제, 학업 스트레스, 전공과 일반적인 특성으로 구성되었다. 수집 된 데이터는 기술 통계, 피어슨 상관 계수, 다중 회귀 분석을 통해 분석되었다. 본 연구에서는 취업 스트레스 $(\beta=-.08, p=.001)$, 음주 문제 $(\beta=-.47, p<.001)$, 학업 스트레스 $(\beta=.15, \mathrm{p}=.006)$ 는 적절음주자기효능감에 영향을 미쳤다. 본 연구를 바탕으로 대학생의 조기 음주 문제 파악을 위해 대학생의 적절음주자기효능감 검사가 필요함을 알 수 있었다. 또한 적절음주자기효능감에 영향을 미치는 요인 인 음주 문제에 대한 대학 내 클리닉 운영이 필요하며, 학생 상담을 통한 학업 스트레스와 취업 스 트 레스에 대한 해결책을 탐색 할 필요가 있음을 알 게 되었다.

Received: March 04, 2021; $1^{\text {st }}$ Review Result: April 20, 2021; $2^{\text {nd }}$ Review Result: June 7, 2021 Accepted: July 31, 2021 
핵심어: 대학생, 음주문제, 취업 스트레스, 학업 스트레스, 자기효능감

\section{1. 서론}

우리나라 국민 음주형태의 가장 큰 변화는 청소년층과 여성층의 음주율이 증가한다는 사실인데, 그 내용적인 면에서도 평생음주율, 현재음주율 뿐만 아니라 위험음주율 및 문제음주율이 유사하게 증가하는 추세를 보이고 있다[1]. 전국 대학생 음주실태조사에 따르면 최근 1 년 동안 1 회 이상 음주한 연간음주율이 성인의 $79 \%$ 와 비교하여 대학생은 $94.4 \%$ 로 더 높았고, 한 자리에서 4-5잔 이상을 마시는 폭음률은 $71.3 \%$, 위험음주(남성 1 일 4잔이상, 여성 1일 3잔이상)를 2주 동안 1-2회 경험한 수시 폭음자가 $42.3 \%, 3$ 회 이상 경험한 상습 폭음자가 28. $9 \%$ 로 나타나서[2] 대학생의 음주문제는 과히 심각함을 알 수 있다.

보편적인 대학생 연령의 음주문제는 청소년과 성인기 사이의 변환기에 위치한 연령적 특성으로 인한 정서적 스트레스, 동료 집단의 압력, 자아정체성 혼란, 낮은 자긍심, 알코 올에 대한 무지 또는 왜곡된 지식, 환경적 스트레스 등으로 음주 문제에 효과적으로 대 처할 수 없기 때문에 다른 연령층에 비해 취약한 상태에 놓여있다. 대학생 음주 형태의 특징은 높은 음주 비율과 폭음, 높은 음주 빈도이다. 많은 수의 사람들이 20 대가 되면서 법의 제약에서 벗어나 음주를 시작하게 된다. 우리나라 대학생들은 입시 스트레스로부터 의 해방과 함께 대학입학과 동시에 음주가 허용되는 분위기로 신입생 환영회, 동아리, MT, 대학축제 등의 대학 생활의 일상에서 쉽게 음주를 경험할 수 있다. 이러한 대학생의 음주 문화는 개인의 잘못된 음주 습관으로 이어지기 쉬우며 학업 능률의 저하 및 건강에 지장을 초래하게 될 뿐만 아니라 사회적으로 폭음, 음주관련 사건 사고의 주요 원인이 되고 있다[3]. 대학생의 음주문제는 음주자 개인의 건강상의 문제, 학업 및 대인관계 뿐 아니라 사회문제까지도 야기할 수 있다[4][5].

지속적인 음주와 폭음은 불면, 손 떨림, 공포감, 경련, 환시 등을 경험하게 되며 학업 상에서는 음주 다음날 지각 혹은 결석을 하거나 집중력과 기억력이 감퇴하여 공부에 지 장을 주는 문제를 일으키게 된다. 대학생들이 대학생활에서 가장 많이 경험하는 스트레 스로 학업, 인간관계, 진로, 취업 등으로 알려져 있다[6][7]. 그중에서도 학업 스트레스는 개인의 대응 차원을 넘어서는 학업과 관련된 과제가 수행되었을 때 나타나며 시험을 치 르거나 앞두고 있을 때 가장 높은 수치를 보고하고 있다[8]. 즉 시험관련 스트레스는 모 든 학생들이 겪는 가장 보편인 스트레스이다. 학생의 스트레스와 음주행동은 관계가 있 다. 박종순[9]도 개인이나 가족 요인, 심리 요인, 사회 요인, 사회 문화 요인들이 학생의 문제음주에 영향을 미치고 있음을 확인하였고, 이를 통해 스트레스와 음주행동이 연계되 어 있음을 확인하였다. 김인[10]은 학들의 스트레스, 폭음, 단독음주 정도에 따른 음주문 제의 차이를 연구하였으며, 그 결과 폭음이나 단독음주자들이 음주문제를 더 많이 보고 하고 있음을 밝혀냈다.

음주는 개인이 경험하는 스트레스와 밀접하게 연관되어 있다. 사람들이 스트레스에 대 한 대처기제로써 음주를 한다는 것은 많은 연구에서 드러난 결과일 뿐만 아니라 일반적 인 사람들의 인식이기도 하다. 스트레스와 음주와의 관계를 설명하는 대표적인 이론인 Conger[11] 의 긴장감소 이론에 따르면 사람들은 긴장 감소와 안도감을 경험하기 위해 음 
주를 한다. 그리고 스트레스 상항에 노출되면 알코올의 섭취를 증가시킨다. 대학생의 스 트레스는 대학생의 학업생활, 가치판단, 장래 및 진로 문제에 대한 불안감이다. 고등학교 시기까지의 지시와 타율에 의한 수동적 생활패턴에서 대학진학과 더불어 변화된 대학생 활에 스스로 적응해야하고, 본인에게 생긴 모든 문제에 대해서 효과적으로 해결해 나가 야하는 문제해결 능력 등을 갖추어야한다. 주변 환경들로부터 스스로 책임져야하며 독립 적이고 능동적인 생활양식으로 전환하도록 요구받게되는데, 이러한 요구는 학생들의 생 활방식과 가치관에 변화를 초래하고 나아가 스트레스를 유발하게 된다.

이렇듯 대학생의 음주는 다양한 요인의 결과와 관련이 있음에도 불구하고, 지금까지의 연구에서 이들 변인을 폭넓게 포함하여 원인을 규명한 연구는 드물었다. 본 연구에서는 대학생의 적절음주자기효능감에 영향을 미치는 요인을 밝혀내어 추후 대학생 음주관련 문제 해결을 위한 중재연구의 근거자료로 활용하고자 실시하였다.

\section{2. 연구방법}

\section{1 연구설계}

본 연구는 대학생의 적절음주자기효능감에 영향을 미치는 요인을 규명하고자 실시된 서술적 조사 연구이다.

\section{2 연구대상}

본 연구 분석에 사용된 자료는 $\mathrm{Y}$ 시에 소재하는 일개 대학의 4 개 학과 학생을 중심으로 편의표집된 학생 265 명의 자료를 분석하였다.

\section{3 연구도구}

본 연구에서는 구조화된 설문지를 연구도구로 사용하였다. 본 연구에서는 음주통제 자기효능감, 적절음주자기효능감, 음주문제, 학업스트레스, 전공적성여부를 설문내용으로 구성하였다. 정의석과 노안영[12]의 취업스트레스, Prochaska와 DiClemente[13]의 자기효능감을 기반으로 Laforge[14] 등이 개발한 음주통제 자기효능감 도구와 Aas등[15]이 개발하고 조희[16]가 수정 보완한 음주거절 자기 효능감을 유주미[17]가 수정보완하여 사용한 적절음주자기효능감 및 음주문제는 술빈도, 술량, 최근음주자제, 일상생활, 기억 유무, 술마심후회를 합한 값으로 하였다. 그외 일반적 특성을 질문하였다.

\section{4 자료 수집 및 분석방법}

자료 수집 기간은 2019년 4월 20일부터 6월 4일까지였고, 수집된 자료는 SPSS WIN 18.0 프로그램을 이용하여 분석하였다. 표본 수는 G*Power 3.1.2 프로그램을 사용하여 다중회귀분석에서 유의수준 .05 , 효과크기 .15 , 검정력 .70 , 예측요인 9 개로 산출한 결과 최소 166 명이 요구되었다. 자료 수집에 앞서 대상자들에게 본 연구의 취지를 설명하고, 자발적으로 참여를 희망하는 대상자에게 자료수집 참여나 중간 포기에 불이익이 없으며, 수집된 자료는 연구이외의 목적에 사용하지 않고, 연구의 종료시, 폐기할 것을 약속하였다. 연구는 3,4학년 참여를 희망하는 대상자에게 실시되었고, 수집된 270 부의 
자료 중에서 설문 작성을 중도 포기한 5 부를 제외한 169 부를 최종 분석에서 사용하였다. 대상자의 일반적 특성은 빈도, 백분율과 Scheffé Test로 사후 분석하였다. 적절음주자기효능감과 관련 변인들은 빈도와 백분율료 분석하였다. 적절음주자기효능감과 관련 변인들은 상관분석으로 분석하고 적절음주자기효능감 영향요인은 회귀분석으로 분석하였다.

\section{3. 결과}

\section{1 대상자의 일반적 특성과 관련요인에 따른 적절음주자기효능감 차이}

대상자의 일반적 특성과 관련요인에 따른 적절음주자기효능감의 차이를 살펴보았다.

대상자는 성별에서 여성이 $61.5 \%(163$ 명)으로 남성 $38.5 \%(102$ 명 $)$ 보다 더 많았고, 평균연령은 22.65세 였으며, 1 학년이 가장 많았고(61.9\%), 3 학년이 가장 적었다(6.0\%).

집에서 생활하는 대상자가 가장 많았고 $(67.2 \%)$, 하숙을 하는 학생이 $8.0 \%$ 로 가장 적었으며, 용돈은 35 만원이상이 $29.4 \%$ 로 가장 많았고, 학생들이 용돈을 가장 많이 사용하는 곳은 식비라고 답한 학생이 가장 많았다(185명).

주로 술을 마시는 요일은 주말이 가장 많았고(53명), 금요일(49명), 요일무시(48명) 순이었다. 간호학과 학생의 참여가 가장 많았으며(164명), 본인전공 선택 이유는 적성 고려가 가장 높았다(107명).

취업에 영향요인으로 본인 의지나 목표가 가장 높았고(45.7\%), 취업 고민을 상담할 상대는 자까운 지인이 $65.3 \%$ 로 가장 높았다.

대상자의 관련요인에 따른 적절음주자기효능감의 차이는 학업스트레스 $(p=.002)$ 와 전공적성 부합 $(\mathrm{p}=.020)$ 에서 유의미한 차이가 있었다. 그러나, 흡연유무 $(\mathrm{p}=.089)$, 운동유무 $(\mathrm{p}=.481)$, 학교생활 만족도 $(\mathrm{p}=.120)$, 음주문화견해 $(\mathrm{p}=.158)$, 건강상태 $(\mathrm{p}=.058)$ 는 유의미한 차이가 없었다.

[표 1] 대상자의 일반적 특성과 관련요인에 따른 적절음주자기효능감 차이 $(\mathrm{N}=265)$

[Table 1] Differences in the Self-efficacy for Moderate Drinking According to the General Characteristics

\begin{tabular}{|c|c|c|c|c|c|c|}
\hline \multirow{2}{*}{ 특성 } & \multirow{2}{*}{$\begin{array}{c}\text { 구분 } \\
(M e a n \pm S D)\end{array}$} & \multirow{2}{*}{$\mathbf{n}$} & \multirow{2}{*}{$\%$} & \multicolumn{3}{|c|}{ 적절음주자기효능감 } \\
\hline & & & & $\operatorname{Mean} \pm$ SD & $\mathbf{t} / \mathbf{F}(\mathbf{p})$ & Scheffé \\
\hline \multirow{2}{*}{ 성별 } & 남 & 102 & 38.5 & $60.90 \pm 11.50$ & \multirow{2}{*}{$.374(.709)$} & \\
\hline & 여 & 163 & 61.5 & $60.39 \pm 10.54$ & & \\
\hline \multirow[t]{2}{*}{ 연령 } & $22.65 \pm 4.82$ & - & - & & & \\
\hline & 1학년 & 164 & 61.9 & $60.62 \pm 11.15$ & & \\
\hline \multirow[t]{2}{*}{ 학년 } & 2학년 & 57 & 21.5 & $59.44 \pm 10.71$ & $.541(.655)$ & \\
\hline & 3학년 & 16 & 6.0 & $60.63 \pm 9.15$ & & \\
\hline
\end{tabular}




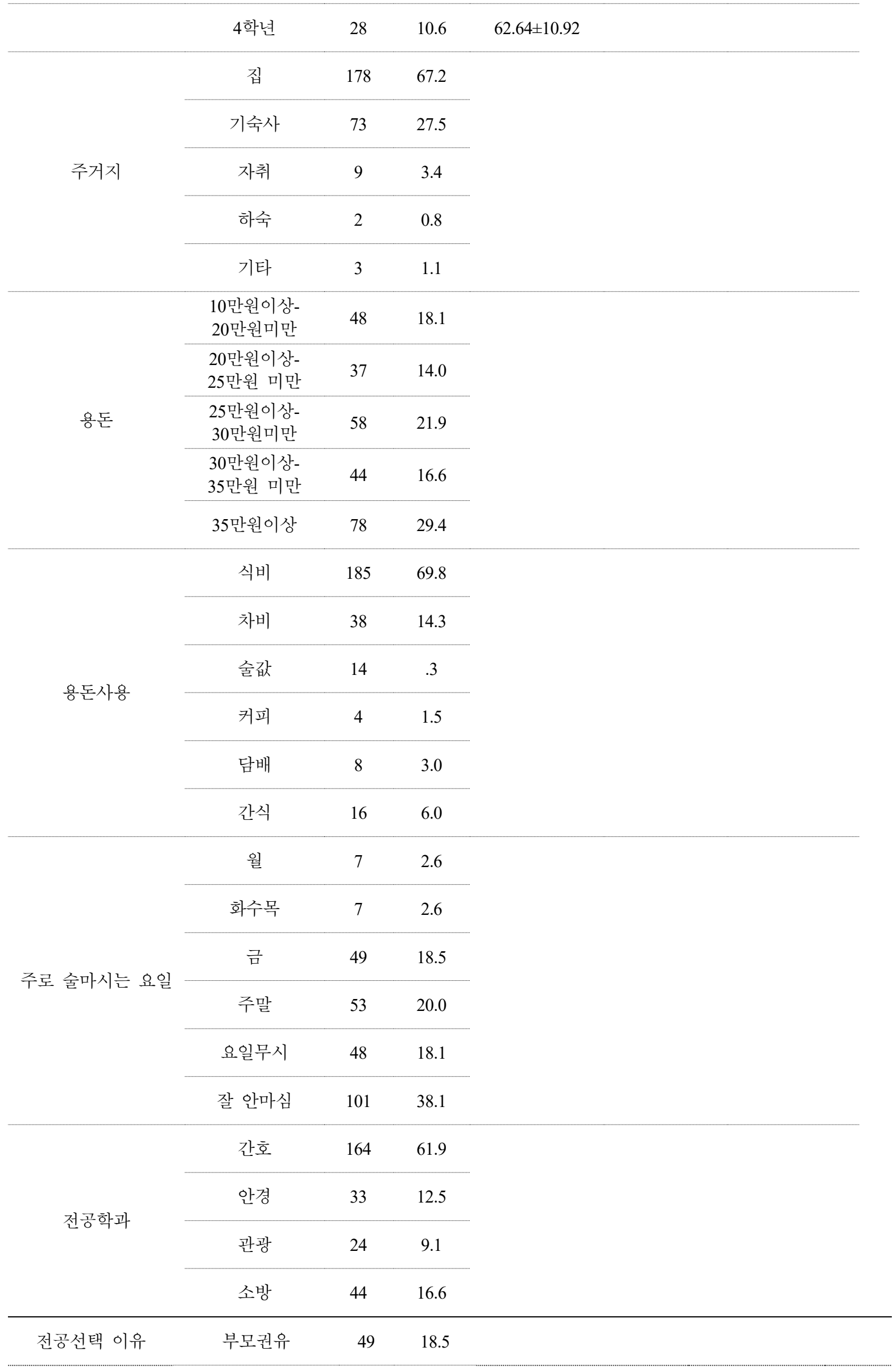




\begin{tabular}{|c|c|c|c|c|c|c|}
\hline & 취직수월 & 77 & 29.1 & & & \\
\hline & 적성 & 107 & 40.4 & & & \\
\hline & 성적 & 9 & 3.4 & & & \\
\hline & 기타 & 23 & 8.7 & & & \\
\hline \multirow{2}{*}{ 취업준비정도 } & 보통 이상 & 134 & 50.6 & & & \\
\hline & 보통 미만 & 131 & 49.4 & & & \\
\hline \multirow{5}{*}{$\begin{array}{l}\text { 본인인지 취업 } \\
\text { 영향요인 }\end{array}$} & 실력 & 96 & 36.2 & & & \\
\hline & 의지나 목표 & 121 & 45.7 & & & \\
\hline & 배경 & 29 & 10.9 & & & \\
\hline & 학교지명도 & 13 & 4.9 & & & \\
\hline & 기타 & 6 & 2.3 & & & \\
\hline \multirow{2}{*}{ 진로상담 유무 } & 있음 & 129 & 48.7 & & & \\
\hline & 없음 & 136 & 51.3 & & & \\
\hline \multirow{4}{*}{ 취업고민 상대 } & 가까운 지인 & 173 & 65.3 & & & \\
\hline & 혼자 & 50 & 18.9 & & & \\
\hline & 걱정안함 & 37 & 14.0 & & & \\
\hline & 기타 & 5 & 1.9 & & & \\
\hline \multirow{2}{*}{ 흡연 유무 } & 흡연 & 58 & 21.9 & $58.43 \pm 10.96$ & \multirow{2}{*}{\multicolumn{2}{|c|}{$-1.709(0.089)$}} \\
\hline & 비흡연 & 207 & 78.1 & $61.19 \pm 10.83$ & & \\
\hline \multirow{5}{*}{ 학업스트레스정도 } & 유 & 124 & 46.8 & $61.09 \pm 10.83$ & \multirow{2}{*}{\multicolumn{2}{|c|}{$.706(0.481)$}} \\
\hline & 무 & 141 & 53.2 & $60.14 \pm 10.97$ & & \\
\hline & 심하다a & 96 & 36.2 & $58.14 \pm 10.16$ & \multirow{3}{*}{$6.24(.002)$} & \\
\hline & 보통이다b & 132 & 49.8 & $61.05 \pm 10.33$ & & $\mathbf{c}>\mathbf{a}$ \\
\hline & 심하지 않다c & 37 & 14.0 & $65.30 \pm 13.05$ & & \\
\hline \multirow{3}{*}{ 학교생활만족도 } & 만족한다a & 120 & 45.3 & $61.93 \pm 11.22$ & \multirow{3}{*}{$2.135(.120)$} & \\
\hline & 보통이다b & 112 & 42.3 & $59.95 \pm 10.33$ & & \\
\hline & 만족하지 않는다c & 33 & 12.5 & $57.88 \pm 11.23$ & & \\
\hline 음주문화견해 & 무절제하다a & 79 & 29.8 & $62.48 \pm 12.19$ & $1.859(.158)$ & \\
\hline
\end{tabular}




\begin{tabular}{|c|c|c|c|c|c|c|}
\hline & 보통이다b & 144 & 54.3 & $59.55 \pm 9.67$ & & \\
\hline & 건전하다c & 42 & 15.8 & $60.57 \pm 12.06$ & & \\
\hline \multirow{3}{*}{ 건강상태 } & 좋다a & 133 & 50.2 & $62.17 \pm 10.20$ & \multirow{3}{*}{$2.877(.058)$} & \\
\hline & 보통이다b & 92 & 34.7 & $59.02 \pm 10.69$ & & \\
\hline & 나쁘다c & 40 & 15.1 & $58.90 \pm 12.95$ & & \\
\hline \multirow{3}{*}{ 전공적성부합 } & 안맞다a & 26 & 9.8 & $58.46 \pm 12.47$ & \multirow{3}{*}{$3.983(.020)$} & \multirow{3}{*}{$\mathbf{c}>\mathbf{b}$} \\
\hline & 보통이다b & 115 & 43.4 & $58.92 \pm 9.67$ & & \\
\hline & 맞다c & 124 & 46.8 & $62.57 \pm 11.36$ & & \\
\hline
\end{tabular}

\section{2 대상자의 취업스트레스, 음주문제 및 적절음주자기효능감 정도}

대상자의 취업스트레스는 40.19, 음주문제는 11.71 , 적절음주자기효능감은 60.58 이고, 그 중 음주통제자기효능감은 36.03 , 음주거절자기효능감은 24.55 이었다.

[Table 2] 대상자의 취업스트레스, 음주문제 및 적절음주자기효능감 정도 $(\mathrm{N}=265)$

[Table 2] Employment Stress, Drinking Problem and the Self-efficacy for Moderate Drinking Level

\begin{tabular}{|c|c|c|c|}
\hline 변수 & 하위변수 & $\operatorname{Mean} \pm$ SD & Min-Max \\
\hline 취업스트레스 & & $40.19 \pm 9.57$ & $15-64$ \\
\hline 음주문제 & & $11.71 \pm 3.83$ & $6-22$ \\
\hline \multirow[t]{3}{*}{ 적절음주자기효능감 } & & $60.58 \pm 10.90$ & $33-85$ \\
\hline & 음주통제자기효능감 & $36.03 \pm 6.74$ & $21-50$ \\
\hline & 음주거절자기효능감 & $24.55 \pm 5.75$ & $9-35$ \\
\hline
\end{tabular}

\section{3 대상자의 취업스트레스, 음주문제 및 적절음주자기효능감 간의 상관관계}

대상자의 적절음주자기효능감과 취업스트레스 $(\mathrm{r}=-0.232, \quad \mathrm{p}<.001), \quad$ 음주문제 $(\mathrm{r}=-0.489$, $\mathrm{p}<.001)$ 는 유의한 상관을 보였다.

[Table 3] 대상자의 취업스트레스, 음주문제 및 적절음주자기효능감 간의 상관관계 $(\mathrm{N}=265)$ [Table 3] Correlation between Employment Stress, Drinking Problem and the Self-efficacy for Moderate Drinking 


\begin{tabular}{|c|c|c|c|}
\hline \multirow{2}{*}{ 변수 } & 적절음주자기효능감 & 취업스트레스 & 음주문제 \\
\hline & \multicolumn{3}{|c|}{$\mathrm{r}(\mathrm{p})$} \\
\hline 적절음주자기효능감 & 1 & & \\
\hline 취업스트레스 & $-.232(<.001)$ & 1 & \\
\hline 음주문제 & $-.489(<.001)$ & $.046(.452)$ & 1 \\
\hline
\end{tabular}

\section{4 적절음주자기효능감 영향요인}

대학생의 적절음주자기효능감에 영향을 미치는 요인은 취업스트레스, 음주문제, 학업스트레스 였다. 이들은 적절음주자기효능감을 $29.3 \%$ 설명하는 것으로 나타났다. 그 순서는 음주문제( $\beta=-.470)$, 취업스트레스 $(\beta=-.184)$, 학업스트레스 $(\beta=.148)$ 순이었다.

그러나, 전공적성부합은 유의미하지 않은 결과를 나타내었다( $\mathrm{p}=.984)$

[Table 4] 적절음주자기효능감 영향요인 $(\mathrm{N}=265)$

[Table 4] Factors Influencing the Self-efficacy for Moderate Drinking of Undergraduate Students

\begin{tabular}{|c|c|c|c|c|c|c|c|}
\hline \multirow{2}{*}{ 변수 } & \multirow{2}{*}{ B } & \multirow{2}{*}{ SE } & \multirow{2}{*}{$\beta$} & \multirow{2}{*}{$\mathbf{t}$} & \multirow{2}{*}{$\mathbf{p}$} & \multicolumn{2}{|c|}{ 다중공선성 } \\
\hline & & & & & & 공차 & VIF \\
\hline (상수) & 80.372 & 4.491 & & 17.896 & $<.001$ & & \\
\hline 취업스트레스 & -.210 & .061 & -.184 & -3.430 & .001 & .927 & 1.079 \\
\hline 음주문제 & -1.337 & .150 & -.470 & -8.922 & $<.001$ & .964 & 1.037 \\
\hline 학업스트레스 & 2.394 & .861 & .148 & 2.782 & .006 & .96 & 1.057 \\
\hline 전공적성부합 & .018 & .908 & .001 & .020 & .984 & .895 & 1.117 \\
\hline
\end{tabular}

$\mathrm{R} 2=.304$, Adj.R2=.293 (F=28.382, $\mathrm{p}<.001)$

\section{4. 결론}

본 연구는 일개 대학의 대학생을 대상으로 적절음주자기효능감에 영향을 미치는 요인을 파악하여 추후 대학생 대상 음주관련 문제 해결을 위한 중재 연구에 활용하고자 실시되었다. 본 연구를 통해 취업스트레스가 높을수록 음주문제가 많을수록, 학업 
스트레스가 높을수록 적절 적절음주자기효능감이 더 낮아진다는 것과 이들 변수 중에서 음주문제는 가장 높은 영향을 미침을 알 수 있었다 $(\beta=-0.470)$.

본 연구에서 유의미한 요인은 아니었으나, 실제 술(음주)과 담배(흡연)는 상관성이 아주 높은 물질이다. 추후의 연구에서는 흡연여부와 음주여부, 적절음주자기효능감정도와의 상관성을 함께 분석하여 결과의 차이를 비교해보는 것도 흥미로운 연구일 것으로 사료된다. 음주는 알코올 중독이라는 심각한 중독 문제를 안고 있으므로, 대학 차원에서도 대학생의 적절음주자기효능감을 향상시킬 수 있는 다양한 프로그램 제공의 노력이 필요하며, 대학생 스스로도 음주를 단순한 스트레스 퇴치의 방법으로 선택하기에는 이후 스스로의 건강과 중독으로 인한 생활문제까지로 이어지는 건강위험행동이라는 점에서 경각심을 가질 필요가 있다고 본다.

\section{References}

[1] https://blog.naver.com/moeblog/221396667930, Mar 04 (2018)

[2] The actual condition of drinking among korean university students, The Koran Alcohol Research Foundation, Seoul: S\&Y, (2010)

[3] Sungsoo Chun, Analysis of College Student Binge Drinking and Alcohol-Related Problems, Journal of Korean Alcohol Science, (2002), Vol.3, No.2, pp.221-233.

[4] Surng-Gie Cho, Seung-Ock Jang, Hye-Mee Yoon, Hye-Kyung Lee, Hyun-Sook Choi, Jekarl Jung, National Survey on Alcohol Use and Abuse among Korean University Students, KARF, (2001)

[5] B. Gadzella, Student-life Stress Inventory: Identification of and reaction to stressors, Psychological Reports, (1994), Vol.74, pp.395-490.

[6] Y. Yom, K. E. Lee, Factors affecting eating attitude of female undergraduates in regard to BMI, Journal of Korean Academy of Nursing, (2010), Vol.40, No.5, pp.676-685.

[7] J. K. Hirsch, J. B. Ellis, Differences in life stress and reasons for living among college suicide ideators and non-ideators, College Student Journal, (1996), Vol.30, No.3, pp.377-386.

[8] M. G. Kadapatti, A. H. M. Vijayalaxmi, Stressors of Academic Stress- A Study on Pre-University Students, Indian Journal of Scientific Research, (2012), Vol.3, No.1, pp.171-175.

[9] J. S. Park, A Study on Factors Affecting Problem Drinking of University Students, Korean Public Health Research, (2000), Vol.26, No.4, pp.393-413.

[10] I. Kim, (The) relationships between stress and drinking problems of college students, Graduate School of Pusan University, Master's Thesis, (2011)

[11] J. J. Conger, Reinforcement theory and the dynamics of alcoholism, Quarterly Journal of Studies on Alcohol, (1956), Vol.17, pp.296-305.

[12] E. S. Jeong, A. Y. Roh, A study on relationship among job-seeking stress, depression, self-esteem, and physical health of college students, Student Life Research of Chonnam National University, (2001), Vol.33, pp.85-101, https://counsel.jnu.ac.kr/counsel/index.do

[13] J. O. Prochaska, C. C. DiClemente, J. C. Nocross, In search of how people change. Applications to addictive behaviors, (1992), Vol.47, No.9, pp.1102- 1114, DOI: 10.1037//0003-066x.47.9.1102

[14] R. G. Laforge, J. E. Maddock, J. S. Rossi, Comparison of five methods for alcohol abuse among college students, Annals of Behavioral Medicine, (1998), Vol.20, p.170.

[15] H. Aas, K. I. Klepp, J. C. Laberg, L. E. Aaro, Predicting adolescents' intentions to drink alcohol: Outcome expectancies 
and self-efficacy, Journal of Studies on Alcohol and Drugs, (1995), Vol.56, No.3, pp.293-299, DOI: $10.15288 /$ jsa.1995.56.293

[16] H. Jo, Developing a predictive model for alcohol consumption behavior among Korean university students, Yonsei University, Doctoral Dissertation, (1999)

[17] Joomi Yu, Effectiveness of Moderate Drinking Education Program for University Students, Graduate School of Mokpo National University, Master's Thesis, (2015) 